\title{
Passing the torch
}

\author{
Andrew S. Wechsler, MD
}

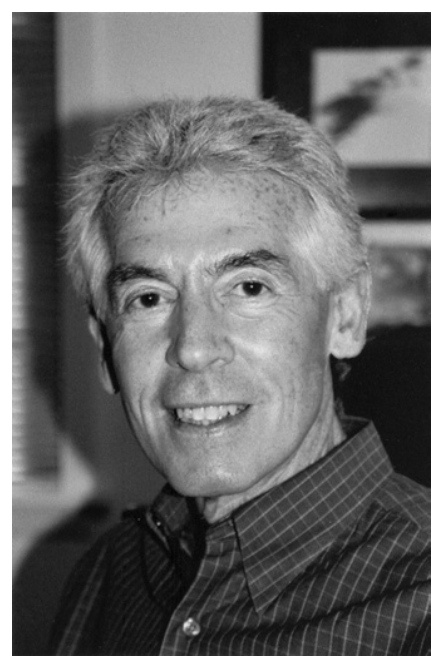

Dr Wechsler
From the Drexel University College of Medicine, Philadelphia, $\mathrm{Pa}$.

Received for publication Sept 26, 2007; accepted for publication Sept 26, 2007.

Address for reprints: Andrew S. Wechsler, MD, Drexel University College of Medicine, Chair, Department of Cardiothoracic Surgery, 230 North Broad Street, Philadelphia, PA 19102-1192 (E-mail: Andrew.Wechsler@ DrexelMed.edu; jtcvs@drexel.edu).

J Thorac Cardiovasc Surg 2007;134:1393-6 0022-5223/\$32.00

Copyright @ 2007 by The American Association for Thoracic Surgery

doi:10.1016/j.jtcvs.2007.09.013
$\mathrm{E}$ ight years ago, the leadership of the American Association for Thoracic Surgery (AATS) granted me the privilege of serving as the seventh editor of The Journal of Thoracic and Cardiovascular Surgery. The time has passed quickly, and because the responsibility for the Journal leadership is about to move into the very able hands of Dr Larry Cohn, I am allowing myself the indulgence of taking a few pages to reflect on what has happened during that time.

Perhaps the single most important decision was to hire Pamela Fried as the managing editor for the Journal. This was the first time in the history of the Association that an editing and publishing professional held this position. It was a critical action, because the Journal was about to undergo the most important change since its inception. Almost global access to the Internet ushered in the era of electronic publishing. This new paradigm resulted in a revolution in the way we did business. Under Pamela Fried's leadership, the Journal transitioned from a world of courier services, facsimile transmissions, and stacks and stacks of paper articles to one inhabited by a fully electronic article submission and review processing system. It was not an easy transition, because the system that we used initially was barely in its beta phase. The evolution to a working system was guided in great part by Pamela Fried. She, in turn, became mentor and psychotherapist for editors, authors, and reviewers. The era of Web 1.0 was fully upon us, and the processes of submission, review, revision, decision, and publication accelerated rapidly.

We redesigned the Journal to make it more attractive and easier to read. We invited video submissions to enhance the understanding of print and electronic content. We allowed authors to publish extensive appendices, figures, tables, and references in the online version of the Journal, thereby controlling article length and gaining more space in the print version. The backlog of articles awaiting publication gradually diminished to the desired quantity: approximately 1.5 issues. We made human studies conform to the principles of the CONSORT document. We made the electronic versions of selected articles available before they appeared in print. We created the "Distinguished Reviewer" program to recognize those reviewers who provided extraordinary service, and we communicated this information to their department heads and school deans.

Change was rapid, and the editor, managing editor, and section editors added a yearly meeting to already busy schedules. We discussed article length, Journal content, editorial responsibilities, and new editorial board members and constantly challenged ourselves with details of the review process, such as the benefits of anonymous versus identified reviews. We introduced an important series of articles, "Statistics for the Rest of Us," to help our readers understand the rapidly developing field of biostatistics. We developed a specially commissioned series of articles dealing with women and outcomes in thoracic surgery and added a section on evolving technology.

With attention to the needs of our readers, we began offering continuing medical education exercises with each issue of the Journal via a program supported jointly by the AATS, Society of Thoracic Surgeons, and European Association for CardioThoracic Surgery. I frequently solicited editorials from thought leaders in our specialty to help provide important perspective on challenging new scientific and clinical topics as they emerged in the Journal. The material submitted annually to the Journal increased by more than $70 \%$ during our 8 years of Journal stewardship, and the Journal office added to its responsibilities the editorial management of 2 AATS publications: Seminars in Thoracic and Cardiovascular Surgery and Operative Techniques in Thoracic and Cardiovascular Surgery. At the same time, the overall mean of months from 


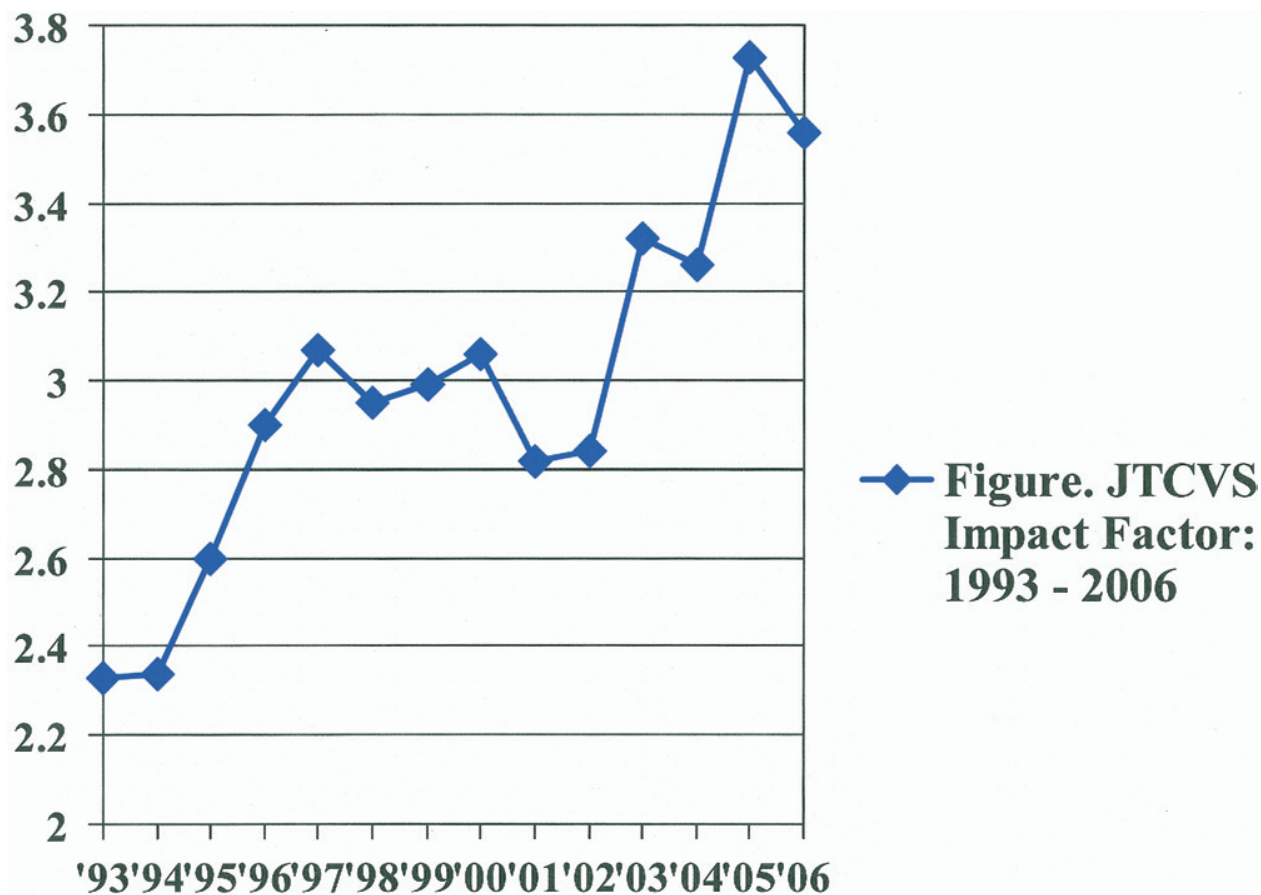

Figure 1. The Journal of Thoracic and Cardiovascular Surgery impact factor: 1993 to 2006.

receipt to decision for original manuscripts decreased $27 \%$ between 2000 and 2006 and the time from submission to publication decreased by almost a month.

The relationship with our publisher, Elsevier, through the management of Joshua Spieler, was cordial and collaborative in every respect. The AATS Council approved the purchase of the Journal from Elsevier, and solid business negotiations by William Maloney and Robert Jones of PRRI resulted in increased pages for the Journal, more color illustrations, and an incentive-based publishing contract designed to provide a timely Journal in an increasingly impatient world.

These efforts and the intellectual productivity of our professional colleagues resulted in a substantial increase in our impact factor (Figure 1). Moreover, as of 2006, the Journal's impact factor was 3.56, and the Journal's impact factor ranks 10th of 138 surgical journals, 12 th of 74 cardiac and cardiovascular system journals, and 7th of 34 respiratory system journals. All of this occurs in a specialty with a relatively small membership base.

At the conclusion of our term of office, we believe that the Journal remains the most important journal of its kind. That being said, I reiterate my frequent comment that we are also fortunate to have 3 major associations: the AATS, European Association for Cardio-Thoracic Surgery, and Society of Thoracic Surgeons and their respective journals. These journals complement rather than compete with one another. They serve subtle but different purposes, and each is led by an editor of extraordinary competence:
Dr L. Henry Edmunds, The Annals of Thoracic Surgery, and Professor Ludwig Von Segesser, the European Journal of Cardiothoracic Surgery and Interactive CardioVascular and Thoracic Surgery publications. The personal relationships with these gentlemen and their capable staffs have been some of the great rewards of my tenure as editor.

None of this happened without hard work, so it seems appropriate to recognize some key individuals in the process. Although too many to mention in this article, our reviewers deserve great praise. We consistently called on the busiest and most committed members of our specialty, here and around the globe. We were rarely let down, and the quality of the published work is a tribute to their diligence, intellect, and generosity. I acknowledged the critical role of peer review in an earlier editorial. ${ }^{1}$

\section{Pamela Fried, Managing Editor}

Pam was the core around which every technical aspect of the Journal was organized, and for many authors and reviewers, hers was the voice or e-mail address associated with the Journal. She possesses the ability to transform any complex concept into a well-designed system that works. She has the capacity to cajole kindly, to micromanage without becoming paralyzed by detail, and to

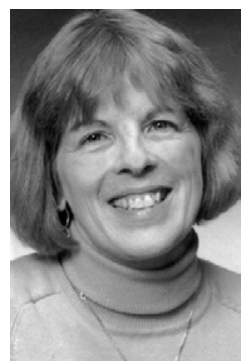


motivate innovation. She assembled a competent, personable editorial staff and inspired their commitment to precision, accessibility, productivity, and loyalty: Assistant Managing Editor Beth Goldner and Editorial Assistants Meg Etherington, Lillian Kuretu, and Nicole McPherson.

\section{Eugene Blackstone, MD, Section Editor for Statistics}

Gene has served continuously as the statistics editor for our Journal for at least 15 years. As biostatistics has evolved, he has helped countless authors through the process of optimizing their data and has made sure that complex analyses have the statistical legitimacy to allow research conclusions to become clinical mandates. His reviews of manuscripts

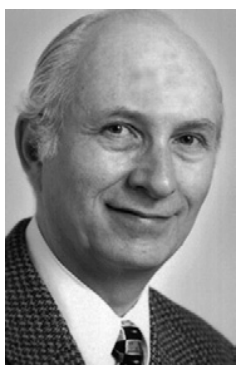
exceeded mere statistical precision and invariably reduced confusing and complex clinical and research problems to highly focused questions with their appropriate answers. He helped countless authors transform well-focused thoughts into crisp hypotheses that were testable. He is the consummate reviewer, statistician, and editor.

\section{Ralph Damiano, MD, Section Editor for Adult Cardiac Studies}

Ralph has dealt with complex basic science investigations, robotics, and arrhythmias, the latter being an area in which he is a leader in his field by virtue of his knowledge and experience. His interest in emerging technology facilitated the development of this new section of the Journal. His wisdom and thoughtfulness have been critical in as-

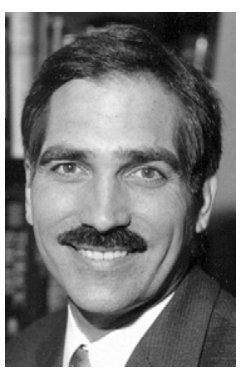
sessing the most intricate of these studies. Frequent editorial contributions helped provide perspective on novel therapies and defined those ready for immediate application versus those requiring further proof of efficacy.

\section{Martin McKneally, MD, Section Editor for Medical Ethics}

Martin served as the Journal's first ethics editor. Unlike many bioethicists, Martin is "one of us": He was a distinguished general thoracic surgeon before developing his scholarly interest in ethics. His balanced and trained approach to ethical issues in our specialty culminated in his responsibility for developing a system to manage conflicts of interest as they emerged from some of our authors. The approach of the Journal to management of conflict of interest was lauded in The Wall Street Journal.

\section{Craig Miller, MD, Section Editor for Adult Cardiac Studies}

In his designated area, Craig was the most active of the associate editors. His encyclopedic knowledge of the literature, personal experience, and eternal vigilance made it possible for the Journal to deal with emerging technologies, such as endovascular therapies and novel valve studies. Frequent e-mails sent at 3:00 a.m. attested to his many

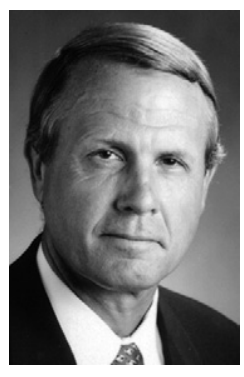
commitments and personal work ethic.

Rarely lacking a strong opinion on any subject, Craig was the resident skeptic who insisted on proof, thoughtful analysis, and humble interpretation of one's own contributions. His pithy analyses had the potential to make any author feel like both student and mentor at the same time.

\section{Alec Patterson, MD, Section Editor for General Thoracic Surgery}

Alec's amazing knowledge of every facet of this component of our specialty was invaluable in maintaining the strength of the Journal in this important area. From basic science to clinical oncology, transplantation, congenital lesions, and infectious problems, there did not seem to be an area where he could be stumped. Thoughtful and fair, he ad-

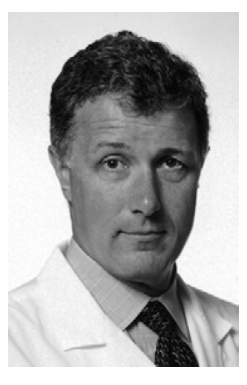
judicated many complex issues on articles of great importance. Alec was an editor who was generous to the authors while insisting on accuracy, detail, and visual representations of alleged "successes." He understood better than most when bad therapy led to a good outcome and made sure that those concepts were not promulgated.

\section{Thomas Spray, MD, Section Editor for Congenital Heart Disease}

Tom's capacity for understanding some of the most complex articles that we received was remarkable. His performance over the 8 years was steady, predictable, timely, and thoughtful. Although not seen by the authors, every decision involved in a brief communication was accompanied by a note to me that justified or explained the basis for his decision. His breadth of knowledge in the field of congenital cardiac surgery is awesome and 
has greatly strengthened the credibility of that section of the Journal.

\section{Richard Weisel, MD, Section Editor for Basic and Translational Science}

Richard's addition as a section editor was a recognition of this important and evolving science. His role was to critique the most complex of the studies in translational science and to protect the welfare of our patients by demanding the highest level of scientific accuracy for any study that might result in application to patients. His thorough knowl-

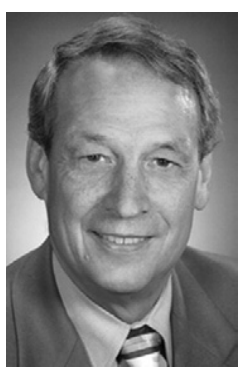
edge of fundamental science prevented premature application of therapies that inadequately balanced discovery and proof while consistently demanding that authors adhere to the most rigorous scientific and ethical principles.

\section{The Editorial Board}

Those individuals invited to join the editorial board all demonstrated great accomplishment in their specialty. Each board member had published extensively, had served the Journal as a reviewer, and was an acknowledged expert in his or her field. Each member of the board signed a commitment to perform serious work for the Journal despite many other obligations. At the last meeting of the editorial board, the average review time for these busy surgical scientists was a remarkable 14 days, and some members of the board had reviewed over 50 articles in the course of the year, many of which required subsequent review. As editor, I am deeply grateful to the members of the editorial board whose collective efforts maintained the high standards of the Journal for scientific accuracy and practicality.

\section{My Faculty Colleagues Former and Current}

Special thanks are due to my former and current colleagues on the cardiothoracic surgical faculty at Drexel University College of Medicine: Drs Percy Boateng, John Entwistle, Karl Grunewald, Albert Guerraty, Ray Kuretu, Rohinton Morris, Louis Samuels, and Michael Strong. At one time or another, each of these fine surgeons had to pick up the slack that accompanied the demanding travel schedule associated with the Editor position. It was always done with graciousness and generosity. The task would have been much more difficult without such support.
During our tenure, we experienced some disappointments. We learned that we had to do a better job of managing conflict of interest as it might exist in our authors, reviewers, and editors. As a result, we established strong and thoughtful policies to reflect the changes in our thinking. We had to deal with authors who published the same work in more than one journal and other authors who falsified documents, performed experiments on patients with inadequate consent, and were excessively creative with the generation of experimental data. Fortunately, such instances were rare, and we were gratified to find that other members of the scientific community were as upset by them as were we. We continue to admire the many authors who conscientiously identify the limitations of their own work and who approach their important contributions with great humility.

Serving as your editor for the past 8 years has been extremely gratifying. Despite the fact that research in our specialty is seriously threatened by a lack of funding and, to a great extent, is inadequately appreciated, there remains a steady stream of novel approaches to the diseases and conditions we are committed to treat. It is clear that department heads at our best institutions are conveying the importance of research to their faculty despite diminishing compensation for clinical activities that stress departmental resources. In the choosing and balancing of material for publication in the Journal, I have tried not to discriminate among excellent clinical science, studies of populations, and fundamental science investigations. I admit to a bias for prospectively randomized trials, both in clinical and basic investigations, because we do not have enough of them in our specialty. With rare exception, post hoc matching techniques do not provide the same quality of information that a well-designed, well-executed prospectively randomized study yields.

Without doubt, the Journal will evolve. It will continue to be an indelible marker of the thought and performance of our specialty at any moment in time and must, therefore, be excellent. I am confident in this vision because I remain convinced that it is the intellect, talent, and commitment of the best in our specialty that have made the Journal what it is today and what it will be in the future.

\section{Reference}

1. Wechsler AS. Peer review: Recognition and responsibility. $J$ Thorac Cardiovasc Surg. 2001;122:419-20. 